\title{
Mortality in participants and non-participants of a multifactorial prevention study of cardiovascular diseases: a 28 year follow up of the Helsinki Businessmen Study
}

Timo E Strandberg, Veikko V Salomaa, Hannu T Vanhanen, Vesa A Naukkarinen, Seppo J Sarna, Tatu A Miettinen

\begin{abstract}
Objective-To investigate pretrial risk factors and long term mortality (1964-1992) in participants and nonparticipants of a multifactorial primary prevention trial.
\end{abstract}

Design-A prospective study among 3313 initially healthy businessmen. During the 1960s (1964 onwards), 3490 healthy male business executives born between 1919 and 1934 participated in voluntary health checks at the Institute of Occupational Health in Helsinki. From that period cardiovascular disease (CVD) risk factors were available in 3313 men. In the beginning of the 1970s these men were invited to join a multifactorial primary prevention trial of CVD. Six groups were formed: (I) healthy participants in a high risk intervention group $(n=612)$, and (II) their randomised control group $(n=610)$; (III) a non-participant low risk group (n = 593); (IV) an excluded group with signs of CVD ( $(n=563)$; (V) a refused group $(n=$ 867); and (VI) dead $(n=68)$. Groups I and II participated in the five year prevention trial which started in 1974. Other groups were followed up through registers, with no personal contact.

Medicine, University of Helsinki, Helsinki, Finland

T E Strandberg

$\mathrm{H}$ T Vanhanen

T A Miettinen

National Public Health Institute, Helsinki, Finland V V Salomaa

Department of Medicine, Jorvi Hospital, Espoo, Finland

V A Naukkarinen

Department of Public Health, University of Helsinki, Helsinki, Finland

S J Sarna

Correspondence to:

Dr Timo E Strandberg,

Department of Medicine,

Department of Medicine,

00290 Helsinki, Finland

Accepted for publication

22 May 1995 ( $n=163)$ by smoking only; and violent deaths $(n=83)$ by none of the risk factors. One-hour postload glucose was significantly associated with total mortality in the intervention group only. When the intervention and control groups were included in the same model, the effect of group on total mortality tended to be dependent on the $1 \mathrm{~h}$ blood glucose value $(P=0.06$ for the group by $1 \mathrm{~h}$ glucose interaction term).

Conclusion-The traditional risk factors (smoking, blood pressure, and cholesterol) are significantly associated with 28 year mortality in this high social class population with previous health education. Conversely, a "clustering" of low risk factors predicted low total, coronary, and cancer mortality. The findings on $1 \mathrm{~h}$ blood glucose suggest that factors related to glucose tolerance explain in part the excess mortality in the intervention group compared with the control group.

(Br Heart f 1995;74:449-454)

Keywords: cardiovascular disease prevention; mortality; mortality in non-participants

Several multifactorial prevention studies aimed at reducing cardiovascular diseases were started during the 1970 s. $^{1}$ One of these was the Helsinki Businessmen Study which employed a five year treatment period to modify risk factors. ${ }^{2}$ Despite effective lowering of risk factor levels by the intervention methods, the 15 year follow up revealed a significantly higher total, cardiac, and violent mortality in the intervention group than in the control group. ${ }^{3}$ The reasons for the unexpected results were not readily explained by analyses of risk factors and drug treatments, and therefore explanations have been sought from play of chance or unsuccessful randomisation. ${ }^{4-6}$ Various interpretations of the study results, for example falsely linking increased coronary heart disease and violent deaths to the treatment of hypercholesterolaemia, may even have led to undue pessimism about reducing cardiovascular risk factors. ${ }^{7}$ Because of this discussion we became interested in analysing the results in their epidemiological context, that is, in the whole "background" 
population consisting of over 3300 businessmen. In contrast to most prevention studies, the Helsinki Businessmen Study has the unique possibility of yielding pretrial risk factor levels and reliable 28-year follow up data of participants and non-participants alike, including men who were excluded because of low levels of risk factors and even those who refused to participate in the prevention study.

\begin{abstract}
Methods
Altogether 3490 men, mostly business executives born in 1919-1934, participated in health checks during the 1960s (1964 onwards) at the Institute of Occupational Health, Helsinki. Initially all men were professionally active and without serious disease. The degree of self selection was probably high as the health checks were voluntary and were performed only in Helsinki. The health checks included clinical examination, ergometry, and laboratory tests. According to the results the men were given health education to improve their cardiovascular disease risk factors. The present study includes the 3313 men (95\% of all, the "background population") from whom risk factor levels were available, and who were subsequently divided to six groups in $\mathbf{1 9 7 4}$ (fig 1). During 1973-1974 all these men were evaluated in order to find healthy volunteers with cardiovascular disease risk factors for a multifactorial primary prevention trial. Inclusion criteria for the trial have been described in detail earlier. ${ }^{2}$ After the selection procedures, the following six groups were formed. The inclusion criteria were met by 1222 healthy men who were randomised to (I) an intervention group ( $n=612)$ and (II) a control group $(n=610)$. The risk factor criteria were not fulfilled by (III) 593 volunteers (the "low risk" group). Another excluded group (IV, $n=563$ ) had symptoms suggestive of cardiovascular disease in the Rose questionnaire $(51 \%)$, were on regular medications
\end{abstract}

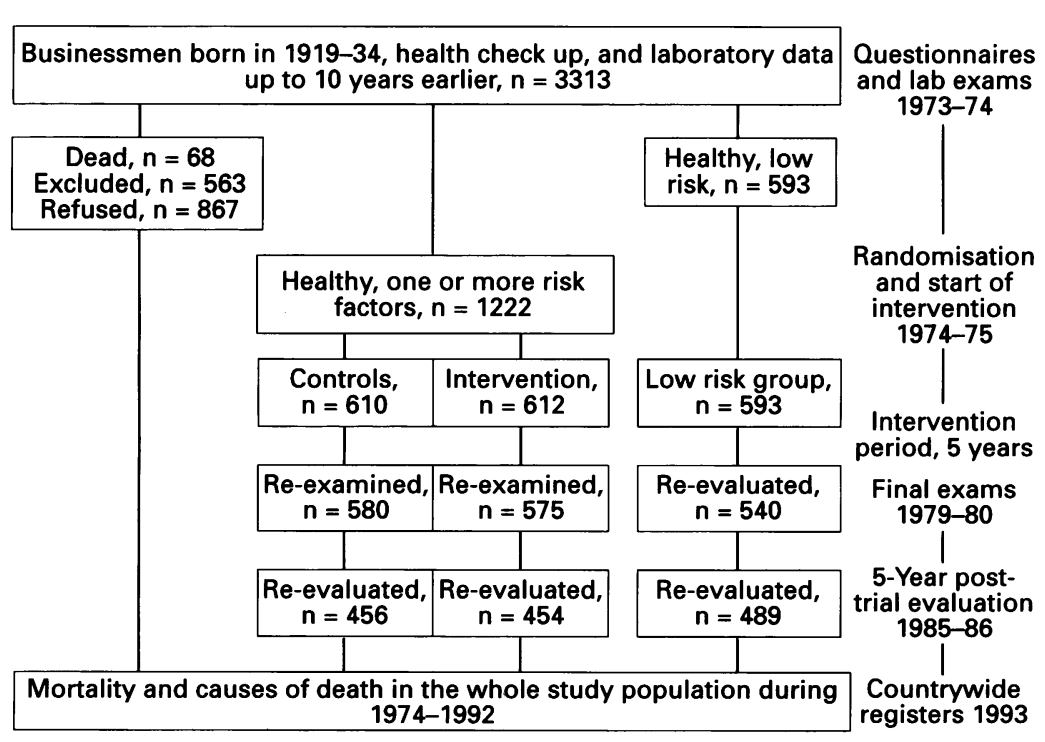

Figure 1 The Helsinki Businessmen Study 1964-1992
(20\%), or fulfilled other exclusion criteria $(20 \%)$. Only 53 of them (9\%) were excluded because of a history of myocardial infarction (35 men) or ischaemic stroke (18 men). The invitation to tests was refused or not responded to by (V) 867 men (the "refused" group). Group VI consisted of the 68 men out of the 3313 who had died by 1974 . Between 1974 and 1980 the intervention and control groups participated in the five year multifactorial prevention trial. These groups and the low risk group were re-evaluated in 1979-1980 and in 1985-86. ${ }^{8}$ Risk factors of the excluded group (IV) and the refused group (V) have not been explored after 1974 .

Mortality up to December 31, 1992, in the whole population of 3313 men was determined using the countrywide computerised cause of death register of the Central Statistical Office of Finland. Assessment of vital status is thus $100 \%$ complete. Because the population was defined in 1974 as those who were born between 1919 and 1934 and attended at least one health check between 1964 and 1974, the follow up is partly retrospective. Thus we have used two follow up times in this report. (1) Although the mean year of first visit was 1968 , a few men belonging to the background population died before that. Therefore we chose the year 1964 (all of the population alive) as the formal start of the follow up involving the whole background population of 3313 men. (2) In the analyses concerning the five groups formed in 1974 and described above, we have used the year 1974 as the start of follow up.

Standard BMDP statistical software ${ }^{9}$ was used for analyses. Mortality differences between the groups were compared using Kaplan-Meier survival curves (BMDP program 1L). Relative risks (hazard ratio, $R R$ ) with their $95 \%$ confidence intervals (CI) for mortality associated with different initial risk factors were calculated using Cox's model (BMDP 2L).

\section{Results}

RISK FACTOR LEVELS IN THE GROUPS IN THE 1960s

Earlier risk factor levels determined in the 1960 s for the different groups defined in 1974 are shown in table 1 . The age profiles were roughly comparable. The low risk group-as expected-already had the lowest risk score in the 1960s, whereas the highest and second highest risk scores were observed among the men who had died by 1974 and in the excluded group, respectively. The risk scores were roughly similar in the control, intervention, and refused groups. Smoking tended to be more prevalent in the refused group, which included both low risk individuals and individuals with illnesses.

MORTALITY IN DIFFERENT GROUPS

Among the 68 men who had died by 1974 the most frequent causes were violence (34\%), cardiac disease $(31 \%)$, and malignant disease (18\%). During 1974-1992, total, cardiac, and 
Table 1 Pretrial risk factor levels in the groups defined in 1974

\begin{tabular}{|c|c|c|c|c|c|c|}
\hline Risk factor * & $\begin{array}{l}\text { Low risk group } \\
(n=593)\end{array}$ & $\begin{array}{l}\text { Control } \\
(n=610)\end{array}$ & $\begin{array}{l}\text { Intervention } \\
(n=612)\end{array}$ & $\begin{array}{l}\text { Excluded } \\
(n=563)\end{array}$ & $\begin{array}{l}\text { Refused } \\
(n=867)\end{array}$ & $\begin{array}{l}\text { Dead in } 1974 \\
(n=68)\end{array}$ \\
\hline Age in 1974 (years) & $47(4)$ & $48(4)$ & $48(4)$ & $49(4)$ & $48(4)$ & $50(4)$ \\
\hline Body mass index $\left(\mathrm{kg} / \mathrm{m}^{2}\right)$ & $25(2)$ & $26(3)$ & $26(3)$ & $26(3)$ & $26(3)$ & $26(3)$ \\
\hline $\begin{array}{l}\text { Blood pressure }(\mathrm{mm} \mathrm{Hg}) \\
\text { Systolic } \\
\text { Diastolic }\end{array}$ & $\begin{array}{c}130(11) \\
83(7)\end{array}$ & $\begin{array}{c}135(15) \\
86(9)\end{array}$ & $\begin{array}{c}135(13) \\
86(9)\end{array}$ & $\begin{array}{r}144(20) \\
92(13)\end{array}$ & $\begin{array}{r}136(17) \\
86(10)\end{array}$ & $\begin{array}{r}147(22) \\
93(15)\end{array}$ \\
\hline Cholesterol $(\mathrm{mmol} / \mathrm{l})$ & $6 \cdot 6(1 \cdot 0)$ & $7 \cdot 4(1 \cdot 3)$ & $7 \cdot 4(1 \cdot 2)$ & $7 \cdot 4(1 \cdot 3)$ & $7 \cdot 2(1 \cdot 3)$ & $7 \cdot 6(1 \cdot 4)$ \\
\hline Triglycerides $(\mathrm{mmol} / \mathrm{l})$ & $\begin{array}{l}1 \cdot 2(0 \cdot 6) \\
\mathrm{n}=211 \dagger\end{array}$ & $\begin{array}{l}1 \cdot 7(1 \cdot 0) \\
\mathrm{n}=260\end{array}$ & $\mathrm{n}=255$ & $\begin{array}{c}1 \cdot 7(1 \cdot 0) \\
\mathrm{n}=399\end{array}$ & $\begin{array}{c}1 \cdot 5(0 \cdot 8) \\
\mathrm{n}=278\end{array}$ & \\
\hline $1 \mathrm{~h}$ Glucose $(\mathrm{mmol} / \mathrm{l})$ & $\begin{aligned} & 5 \cdot 8(1 \cdot 5) \\
n & =479 \dagger\end{aligned}$ & $\begin{array}{l}6 \cdot 4(1 \cdot 8) \\
\mathrm{n}=493\end{array}$ & $\begin{aligned} & 6 \cdot 3(1 \cdot 8) \\
\mathrm{n} & =498\end{aligned}$ & 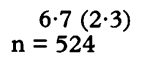 & $\begin{array}{c}6 \cdot 3(2 \cdot 0) \\
\mathrm{n}=701\end{array}$ & 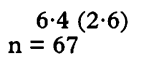 \\
\hline Smokers $(\%) \ddagger$ & $24 \cdot 8$ & $43 \cdot 1$ & $44 \cdot 5$ & $45 \cdot 7$ & $46 \cdot 9$ & $52 \cdot 1$ \\
\hline Risk score $\oint$ & $12(8)$ & $22(17)$ & $21(18)$ & $29(28)$ & $21(22)$ & $43(50)$ \\
\hline
\end{tabular}

^Data are mean (SD).

tn $=$ number with measurement.

\Calculated according to $\mathrm{Keys}^{10}$ (risk of cardiac death or $\mathrm{Q}$ wave infarction per 5 years and $1000 \mathrm{men}$ ).

cancer mortality was lowest in the low risk group (fig 2, table 2). Total mortality was highest in the excluded group, even without the 53 men who had had a non-fatal infarction or stroke before 1974 (data not shown); the second highest mortality was observed in the refused group. Not only cardiac but also cancer mortality was highest in these two groups. Between the intervention and control groups significant differences were observed in the 18 year total (RR $1.46,95 \%$ CI 1.08 to 1.96 ), coronary (RR $2 \cdot 05,95 \%$ CI 1.20 to 3.50 ), and violent deaths (RR 15.9, 95\% CI $2 \cdot 12$ to $120 \cdot 0$, table 2 ). We should point out,

Figure 2 Kaplan-Meier survival curves up to 31 December, 1992, of the groups defined in 1974. 1. Low risk group; 2. Control group; 3. Intervention group; 4. Refused group; 5. Excluded group. Difference between groups: $P<0.001$ (Wilcoxon).

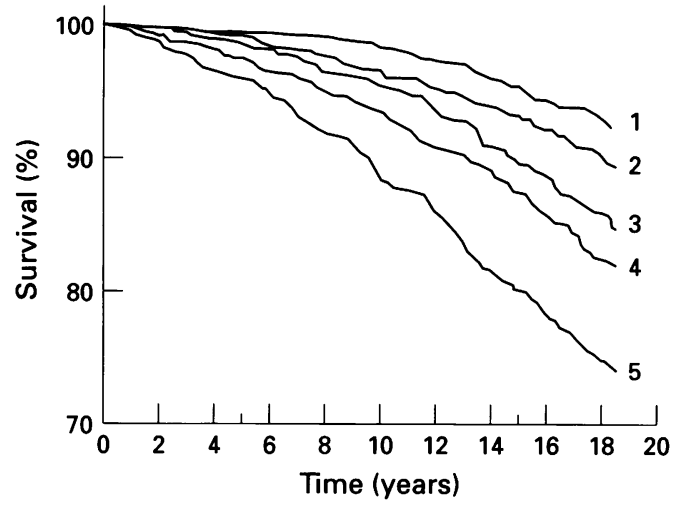

however, that the incidence of violent deaths is similar in the low risk and intervention groups, and there tended to be more deaths in the refused group than in the intervention group (RR $1 \cdot 16,95 \%$ CI 0.92 to $1 \cdot 46$; table 2, fig 2).

\section{FACTORS ASSOCIATED WITH MORTALITY} DURING FOLLOW UP

The associations between initial risk factors and mortality were examined in all 3313 men for the 28 year (1964-1992) follow up period. Total deaths were significantly predicted by age (RR $1.48,95 \%$ CI 1.31 to $1 \cdot 66$ ), systolic blood pressure (RR $1 \cdot 18,95 \%$ CI $1 \cdot 13$ to $1 \cdot 24$ ), serum cholesterol (RR $1 \cdot 11,95 \%$ CI 1.04 to $1 \cdot 19$ ), and smoking (RR $1 \cdot 87,95 \% \mathrm{CI}$ 1.55 to 2.25 ); coronary deaths by age ( $R R$ $1 \cdot 44,95 \%$ CI $1 \cdot 19$ to $1 \cdot 75$ ), systolic blood pressure (RR $1 \cdot 24,95 \%$ CI $1 \cdot 15$ to $1 \cdot 34$ ), and cholesterol (RR $1 \cdot 26,95 \%$ CI $1 \cdot 13$ to $1 \cdot 41$ ). Cancer deaths were significantly predicted by age (RR $2 \cdot 20,95 \%$ CI 1.76 to $2 \cdot 76$ ) and smoking (RR $3 \cdot 45,95 \%$ CI $2 \cdot 38$ to $4 \cdot 99$ ). No significant associations were observed between the measured risk factors (including cholesterol) and violent (non-illness) deaths. Since $1 \mathrm{~h}$ postload glucose was determined in only 2762 men in the 1960 s, relative risks associated with this criterion were assessed separately (but using all the other risk factors

Table 2 Deaths during the 18 year (1974-1992) follow up of the study groups

\begin{tabular}{|c|c|c|c|c|c|}
\hline Death $^{*}$ & $\begin{array}{l}\text { Low risk group } \\
(n=593)\end{array}$ & $\begin{array}{l}\text { Control group } \\
(n=610)\end{array}$ & $\begin{array}{l}\text { Intervention } \\
(n=612)\end{array}$ & $\begin{array}{l}\text { Excluded } \\
(n=563)\end{array}$ & $\begin{array}{l}\text { Refused } \\
(n=867)\end{array}$ \\
\hline Coronary heart disease & $15 \cdot 2(9)$ & $31 \cdot 1(19)$ & $63 \cdot 7(39)$ & $119.0(67)$ & $50 \cdot 7(44)$ \\
\hline Ischaemic stroke & $1.7(1)$ & $3 \cdot 2(2)$ & $0(0)$ & $12 \cdot 4(7)$ & $12 \cdot 7(11)$ \\
\hline Intracranial haemorrhage & $1 \cdot 7(1)$ & $6 \cdot \overline{6}(4)$ & $3 \cdot 3(2)$ & $0(0)$ & $0(0)$ \\
\hline Subarachnoid haemorrhage & $1.7(1)$ & $0(0)$ & $0(0)$ & $7 \cdot 1(4)$ & $5 \cdot 8(5)$ \\
\hline Other cardiovascular disease & $1 \cdot 7(1)$ & $1.6(1)$ & $1.6(1)$ & 24.9 (14) & $3.5(3)$ \\
\hline Neoplasms & $28 \cdot 7(17)$ & $47.5(29)$ & $44 \cdot 1(27)$ & $53 \cdot 3(30)$ & $55.4(48)$ \\
\hline Violent deaths & $25 \cdot 3(15)$ & $1.6(1)$ & $26 \cdot 1(16)$ & $21 \cdot 3(12)$ & $18 \cdot 5(16)$ \\
\hline Accidents & $16.9(10)$ & $1.6(1)$ & $21 \cdot 2(13)$ & $16.0(9)$ & $11.5(10)$ \\
\hline Suicide & $6 \cdot 7(4)$ & $0(0)$ & $3 \cdot 3(2)$ & $5 \cdot 3(3)$ & $5 \cdot 8(5)$ \\
\hline Homicide & $1 \cdot 7(1)$ & $0(0)$ & $1.6(1)$ & $0(0)$ & $1 \cdot 2(1)$ \\
\hline Other & $3.4(2)$ & $13 \cdot 1(8)$ & $14 \cdot 7(9)$ & $16.0(9)$ & $30 \cdot 0(26)$ \\
\hline Unknown & (0) & (1) & (1) & (3) & (3) \\
\hline All & $79 \cdot 3(47)$ & $106 \cdot 6(65)$ & $155 \cdot 2(95)$ & $259 \cdot 3(146)$ & $179.9(156)$ \\
\hline
\end{tabular}

*Deaths per 1000 men until 31 December, 1992. Classified according to the Finnish version of the International classification of diseases (ICD-9). The numbers in parentheses indicate absolute events. 
as covariates). In these analyses $1 \mathrm{~h}$ glucose was not significantly associated with the 28 year mortality. Exclusion of the intervention group did not change the results.

Additional age adjusted analyses showed that particularly coronary mortality but also total mortality rose by the cholesterol quintile of the 1960s. RRs for total mortality were $1.00,1.03,1.21,1.18$, and $1.51(95 \% \mathrm{CI}$ $1 \cdot 17$ to 1.95$)$ from the lowest to the highest cholesterol quintile. No association was observed between cholesterol and cancer deaths or violent deaths. Examinations of suicides $(n=23)$ and other non-illness deaths $(n=60)$ separately gave similar results. Further division of the lowest cholesterol quintile with 92 deaths into tertiles (cut off points 5.2 and $5.9 \mathrm{mmol} / \mathrm{l}$ ) showed that the lowest cholesterol level was associated with the lowest risk (RRs 1, 1.4, 1.3).

In stratified analyses examining the risk factors for total mortality in the different groups defined in 1974, smoking was consistently significant (RRs 1.5 to 2.8 compared with nonsmokers; table 3 ). In addition, systolic blood pressure predicted mortality in the excluded and refused groups and marginally so in the control group. Interestingly, while age consistently predicted mortality in other groups (45-70\% increase in $R R$ per five years) the $19 \%$ increase in the intervention group was not statistically significant (table 3). One-hour glucose (logarithmically transformed value) was significantly associated with total mortality in the intervention group ( $R R 16.0,95 \% \mathrm{CI}$ 2.5 to 100.9 ), but not in the other groups. The result was seemingly different from that in the control group (RR $1.01,95 \% \mathrm{CI} 0 \cdot 1$ to 10.6 ), but as the confidence intervals overlapped we also explored the association using an interaction term in the Cox models. These analyses showed that in the combined intervention plus control groups total mortality was significantly associated with $\log 1 \mathrm{~h}$ glucose (RR 5.79, $95 \%$ CI 1.39 to $24 \cdot 17$ ), Keys' risk score (RR $1 \cdot 09,95 \%$ CI 1.01 to $1 \cdot 17$ ), and group (control group 0 , intervention group 1: RR $1.53,95 \%$ CI 1.07 to $2 \cdot 18$ ). When the interaction term $(\log 1 \mathrm{~h}$ glucose $\times$ group) was included in the model the relative risks of group and the glucose were no longer significant, whereas the interaction term approached statistical significance with a $\mathrm{P}$ value of 0.06 .

\section{Discussion}

The unexpected result of the Helsinki Businessmen Study seemed to give a pessimistic impression of multifactorial primary prevention, ${ }^{23}$ and the 18 year results still show a higher mortality in the intervention than in the control group (table 2, fig 2). However, the present analysis of the background population of 3313 men gives an important new perspective on this outcome. The initial setting of the study and the data linkage with the national death register offered a unique chance of obtaining information on pretrial risk factors and survival follow up from men who refused to participate in or were excluded from the actual prevention trial. The present results show that the low risk group-as defined by the cardiovascular risk factor status in the 1960 s and 1974 - continues to have the best prognosis after 18 years. This concerns not only coronary, but cancer and total mortality as well. Furthermore, those who refused the intervention trial fare even worse than the intervention group. On the other hand, smoking, serum cholesterol, and blood pressure also significantly predicted total deaths in this population of high social class. Unexpectedly, baseline smoking (smoker/non-smoker) did not significantly predict coronary mortality (RR 1.22, 95\% 0.89 to 1.67 ), but the effect is probably diluted by smoking cessation over the follow up years. As a whole, the Helsinki Businessmen Study results cannot be interpreted as refuting the current idea of cardiovascular risk factors.

The "cholesterol debate" has particularly involved the issue of associations between low cholesterol and non-cardiovascular mortality. ${ }^{11-13}$ These concerns have been opposed ${ }^{14-16}$ -most recently by the results of the $4 \mathrm{~S}$ (Scandinavian Simvastatin Survival Study ${ }^{17}$ ) -and they were not supported by the present study which showed increasing total mortality with increasing serum cholesterol. Multivariate analyses suggested that a $1 \mathrm{mmol} /$ litre rise in total cholesterol implies an $11 \%$ increase in mortality. The result is in accordance with earlier experience in Finland from

Table 3 Relative risks of total deaths (1974-1992) for initial risk factors in different groups

\begin{tabular}{|c|c|c|c|c|c|c|}
\hline \multirow[b]{2}{*}{ Risk factor } & \multicolumn{6}{|c|}{ Group (number of deaths with complete risk factor data) } \\
\hline & Low risk group (47) & Control (60) & Intervention (95) & Excluded (142) & Refused (95) & All (439) \\
\hline Age, 5 year $\star$ & $1.55 t(1.08$ to 2.23$)$ & $1.70(1.21$ to $2 \cdot 37)$ & $1.19(0.92$ to 1.53$)$ & $1.45(1.07$ to 1.74$)$ & $1.49(1.18$ to $2 \cdot 20)$ & $1.47(1.30$ to 1.65$)$ \\
\hline $\begin{array}{l}\text { Body mass index } \\
5 \mathrm{~kg} / \mathrm{m}^{2}\end{array}$ & $1.37(0.65$ to $2 \cdot 77)$ & $0.82(0.49$ to 1.37$)$ & $1 \cdot 24(0.85$ to $1 \cdot 18)$ & $1.06(0.80$ to 1.40$)$ & $1.08(0.78$ to 1.50$)$ & $1.12(0.94$ to 1.32$)$ \\
\hline $\begin{array}{l}\text { Systolic blood pressure, } \\
10 \mathrm{~mm} \mathrm{Hg}\end{array}$ & $1.18(0.92$ to 1.50$)$ & $1.18(1.00$ to 1.40$)$ & $1.02(0.88$ to $1 \cdot 19)$ & $1 \cdot 14(1.05$ to 1.25$)$ & $1 \cdot 17(1.05$ to 1.31$)$ & $1 \cdot 18(1 \cdot 12$ to $1 \cdot 24)$ \\
\hline Cholesterol, $1 \mathrm{mmol} / 1$ & $0.83(0.62$ to 1.11$)$ & $0.97(0.79$ to $1 \cdot 18)$ & $1.08(0.92$ to 1.27$)$ & $1.16(0.97$ to 1.28$)$ & $1 \cdot 11(0.85$ to $1 \cdot 25)$ & $1 \cdot 10(1.02$ to $1 \cdot 18)$ \\
\hline Smoking, yes/no & $2.27(1.26$ to 4.09$)$ & $2.78(1.62$ to 4.77$)$ & $1.53(1.02$ to 2.30$)$ & $1.69(1.11$ to 2.37$)$ & $1.56(0.99$ to 2.46$)$ & $1.90(1.57$ to 2.30$)$ \\
\hline $1 \mathrm{~h}$ Glucose $1 \mathrm{mmol} / 1 \ddagger$ & $0.30(0.02$ to 5.37$)$ & $1 \cdot 01(0 \cdot 10$ to $10 \cdot 6)$ & $16.0(2.53$ to 100.9$)$ & $3.27(0.87$ to $12 \cdot 4)$ & $0.55(0.09$ to 3.43$)$ & $2 \cdot 53(1 \cdot 10$ to $5 \cdot 81)$ \\
\hline
\end{tabular}

^Interval used in the calculation of the relative risk.

tRelative risks were calculated using the Cox proportional hazards model ( $95 \%$ confidence interval in parentheses)

†Separate model because of missing data on one-hour glucose (measured in 2695 men of these groups). Logarithmic transformed value adjusted for age, body mass index, systolic blood pressure, serum cholesterol and smoking. 
the North Karelia Project ${ }^{18}$ and the Seven Countries Study. ${ }^{19}$ The impact of serum cholesterol on mortality depends on the proportion of coronary deaths in the population. When this proportion is low, the effect of serum cholesterol is weak as well. ${ }^{20}$ This is demonstrated in table 3 , showing the best association in the excluded group which also had the greatest coronary mortality. Several recent studies ${ }^{21-23}$ but not all, ${ }^{24}$ have failed to show an association between low cholesterol and cancer. In our study cancer deaths were not significantly associated with initial cholesterol in different analyses and the group with low risk for cardiovascular disease also had the lowest cancer mortality.

The rate of non-illness deaths (including accidents, suicide, and homicide) was significantly higher in the intervention than in the control group. ${ }^{3}$ On the other hand, a high rate of such deaths was observed in the low risk group. The rates of non-fatal violent events were also similar in these three groups. ${ }^{25}$ The difference between intervention and control groups may thus be due to a chance, that is, an exceptionally low incidence in the control group. It has been suggested that low serum cholesterol or cholesterol lowering is associated with violent death ${ }^{11-13} 26$ but the mechanisms are speculative, and, for example, a recent study from North Karelia did not find this association. ${ }^{27}$ In the Helsinki Businessmen Study population, violent events were not associated with initial serum cholesterol, and in the intervention group fatal and nonfatal violent events were not predicted by intrial hypolipidaemic drug use. ${ }^{25}$ On the other hand, these events were independently associated with use of alcohol, which is an important possible confounding variable.

It has been suggested that the associations observed in some studies between low cholesterol and total or non-cardiovascular deaths are due to confounding factors. ${ }^{28} 29$ In the recent analysis by Law et $a l^{16}$ low cholesterol was associated with excess deaths in community based studies, but not in employed cohorts. In accordance with this, no J curve was observed between cholesterol and total mortality of the whole cohort in the present study of businessmen.

Two findings in the present analyses do not support obvious doubts ${ }^{4}$ that the randomisation of the intervention and control groups could have been unsuccessful. First, as presented in table 1 , the risk factor levels between these two groups were similar before and after randomisation. Second, unlike in the other groups, age was not a significant predictor of deaths in the intervention group (table 3), implying that there were modifying factors (intervention methods) on mortality. Taking into account that both blood pressure and cholesterol predicted mortality in the background population, the significant decrease of these risk factors during the intervention ${ }^{2}$ should have improved prognosis in the intervention group. As this was not the case, a chance finding - such as the low mortality caused by violence in the control group -or more likely something in the intervention methods needs to be considered as a possible explanation for the unexpected result. ${ }^{1}$ The present findings may offer an additional potential clue. As shown in table $3,1 \mathrm{~h}$ glucose significantly predicted mortality in the intervention group but not in the control group, despite similar baseline glucose concentrations and significant weight reduction in the intervention group during the intervention period. ${ }^{2}$ The fact that the effect of group on total and coronary heart disease mortality was no longer significant when the group by 1 $h$ glucose interaction term was added to the model suggests that factors related to glucose tolerance explain a part of the excess mortality in the intervention group compared with the control group. Aspects of the intervention methods-possibly mental stress induced by intense health education in the dominant executives, or blood pressure medications ${ }^{830}$ -may have made individuals with impaired glucose tolerance especially vulnerable.

In conclusion, this study shows that the traditional cardiovascular risk factors ${ }^{31}$ are also important predictors of mortality among men of the highest social class. Cholesterol was specifically associated with cardiac deaths and its impact on total mortality seemed to be determined by the proportion of coronary deaths to total deaths. In this population, where confounding factors (initial diseases, different life styles, or social class) were minimised, no evidence was found for an association between low cholesterol and non-vascular or non-illness deaths. The value of studying homogeneous populations to enhance internal validity has also recently been discussed in the context of body weight and mortality. ${ }^{32}$ However, the important questions remain: what is the optimal treatment to lower the risk factors in primary prevention and what are the target levels for intervention? Apparently the intervention methods were not optimal in the Helsinki Businessmen Study. Consequently, the unconventional results of this trial should-rather than calling for pessimism-stimulate more research to find better intervention methods for the primary prevention of cardiovascular diseases.

We thank Soile and Marja Aarnio for technical assistance. Sigrid och Ane Gyllenbergs Stiftelse is acknowledged for financial support. Presented in part at the 66th Scientific Sessions of the American Heart Association, November 8-11, 1993, Atlanta, Georgia, USA

1 Miettinen TA, Strandberg TE. Implications of recent results of multifactorial primary prevention. Ann Med 1992;24:85-9.

2 Miettinen TA, Huttunen JK, Naukkarinen JK, Strandberg $\mathrm{T}$, Mattila S, Kumlin T, et al. Multifactorial primary prevention of cardiovascular diseases in middle-aged prevention of cardiovascular diseases in middle-aged men. Risk factor changes,

3 Strandberg TE, Saloma VV, Naukkarinen VA, Vanhanen HT, Sarna SJ, Miettinen TA. Long-term mortality after 5-year multifactorial primary prevention of cardiovascular 5-year multifactorial primary prevention of cardiovascular
diseases in middle-aged men. $¥ A M A 1991 ; 266: 1225-9$. diseases in middle-aged men. $\mathcal{F} A M A$ 1991;266:1225-9.
Paul O, Hennekens CH. The latest report from Finland: a Paul $\mathrm{O}$, Hennekens $\mathrm{CH}$. The latest report from Fin
lesson in expectations. $\mathscr{f} A M A$ 1991;266:1267-8.

5 Should clinical trials carry a health warning? [Editorial] Lancet 1991;338:1495-6.

6 Oliver MF. Doubts about preventing coronary heart disease. $B M \mathcal{F}$ 1992;304:393-4.

7 Bassler TJ, Bassler TJ, Newman TJ, et al. Long-term mortality after primary prevention for cardiovascula diseases. $\mathcal{F} A M A$ 1992;267:2183-6.

8 Salomaa V. Long-term effect of primary prevention measures of 
coronary heart disease on the risk factor levels in middle-aged men [thesis]. Helsinki: University of Helsinki, 1988: $1-78$

9 Dixon WJ. BMDP statistical software manual. Berkeley: University of California Press, 1992.

10 Keys A, Aravanis C, Blackburn H, et al. Probability of middle-aged men developing coronary heart disease in five years. Circulation 1972;45:815-28.

11 Muldoon MF, Manuck SB, Matthews KA. Lowering cholesterol concentrations and mortality: a quantitative review of primary prevention trials. BMF 1990;301: review 14.

12 Davey Smith G, Pekkanen J. Should there be a moratorium on the use of cholesterol-lowering drugs? $B M F$ rium on the use

13 Jacobs D, Blackburn H, Higgins M, et al. Report of the conference on low blood cholesterol: mortality associations. Circulation 1992;86:1046-60.

14 Stamler J, Stamler R, Brown WV, et al. Serum cholesterol -doing the right thing. Circulation 1993;88:1954-60.

15 Lewis B, Tikkanen MJ. Low blood total cholesterol and mortality: causality, consequence and confounders. $\mathrm{Am}$ $\mathcal{f}$ Cardiol 1994;73:80-5.

16 Law MR, Thompson SG, Wald NJ. Assessing possible hazards of reducing serum cholesterol. $B M \mathcal{F}$ 1994;308: 373-9.

17 The Scandinavian Simvastatin Survival Study Group. Randomised trial of cholesterol lowering in $\mathbf{4 4 4 4}$ patients with coronary heart disease: the Scandinavian patients with coronary heart disease: the Scandinavin

18 Salonen J. Risk of cancer and death in relation to serum cholesterol: a longitudinal study in an Eastern Finnish
population with high overall cholesterol level. $\mathrm{Am} \mathcal{F}$ Epidemiol 1982;116:622-30.

19 Pekkanen J, Nissinen A, Punsar S, Karvonen MJ. Shortand long-term association of serum cholesterol with mortality. Am ₹ Epidemiol 1992;135:1251-8.

20 Frank JW, Red DM, Grove JS, Benfante R. Will lowering population levels of serum cholesterol affect total mortality? F Clin Epidemiol 1992;45:333-46.

21 Chen Z, Peto R, Collins R, MacMahon S, Lu J, Li W. Serum cholesterol concentration and coronary heart disease in population with low cholesterol concentrations.
BMF 1991;303:276-82.

22 Kromhout D, Bosschieter EB, Drijver M, Lezenne Coulander C. Serum cholesterol and 25-year incidence of and mortality from myocardial infarction and cancer. Arch Intern Med 1988;148:1051-5.

23 Davey Smith G, Shipley MJ, Marmot MG, Rose G Plasma cholesterol concentration and mortality. The Whitehall Study. $¥ A M A$ 1992;267:70-6.

24 Chyou PH, Nomura AM, Stemmermann GN, Kato I. Low serum cholesterol and cancer among Japanese American men. $₹$ Clin Epidemiol 1992;45:287-92.

25 Strandberg TE, Miettinen TA. Fatal and non-fatal violent events in 15-year follow-up of multifactorial primary prevention of cardiovascular diseases: the Helsinki Businessmen Study. In: Low blood cholesterol-health implications. Proceedings of a Meeting held in Milan July 1993. London: Current Medical Literature, 1993:40-2.

26 Lindberg G, Råstam L, Gullberg B, Eklund GA. Low serum cholesterol concentration and short-term mortality from injuries in men and women. $B M 71992 ; 305: 277-9$.

27 Vartiainen E, Puska P, Pekkanen J, Tuomilehto J, Lönnqvist J, Ehnholm C. Serum cholesterol concentration and mortality from accidents, suicides, and other violent deaths. $B M F$ 1994;309:445-7.

28 Chen Z, Keech A, Collins R, et al. Prolonged infection with hepatitis $B$ virus and association between low blood cholesterol concentration and liver cancer. BMF 1993; 306:890-4.

29 Iribarren C, Dwyer JH, Burchfiel CM, Reed DM. Can the U-shaped relation between mortality and serum cholesterol be explained by confounding? [abstr] Circulation 1993;87:7.

30 Salomaa VV, Strandberg TE, Vanhanen H, Naukkarinen V, Sarna S, Miettinen TA. Glucose tolerance and blood pressure: a long-term follow-up study in middle-aged men. $B M F$ 1991;302:493-6.

31 Manson JE, Tosteson H, Ridker PM, et al. The primary prevention of myocardial infarction. N Engl f Med 1992; 326:1406-16.

32 Lee IM, Manson JE, Hennekens CH, Paffenbarger RS Body weight and mortality. A 27-year follow-up of middle-aged men. $¥ A M A$ 1993;270:2823-8. 